\title{
EFEITO DA ADIÇÃO DE ÓLEOS MINERAL E VEGETAL A ACARICIDAS NO CONTROLE DO ÁCARO-DA-LEPROSE DOS CITROS Brevipalpus phoenicis (GEIJSKES) (ACARI: TENUIPALPIDAE) ${ }^{1}$
}

\author{
CAROLINA PIRAJÁ DE OLIVEIRA², CARLOS AMADEU LEITE DE OLIVEIRA², WANDERLEY JOSÉ DE MELO³
}

\begin{abstract}
RESUMO - Com a finalidade de esclarecer os efeitos da adição de óleo vegetal e mineral aos acaricidas foi conduzido um ensaio de campo em 1994 no município de Viradouro, SP, utilizando-se de Assist, Triona e Natur'l Óleo, na dosagem de $500 \mathrm{~mL}$ por 100 litros de água, adicionados aos acaricidas: pyridaben nas formulações $200 \mathrm{CE}$ e $750 \mathrm{PM}$, nas dosagens de $75 \mathrm{~mL}$ e $20 \mathrm{~g}$; propargite $720 \mathrm{CE}$ a $100 \mathrm{~mL}$; óxido de fenbutatina $500 \mathrm{SC}$ a $80 \mathrm{~mL}$ e cyhexatin $500 \mathrm{PM}$ a $50 \mathrm{~g}$. O delineamento estatístico adotado foi o de blocos casualizados. As aplicações foram feitas com pulverizador tipo pistola. Após a preparação da calda, foi determinado o pH. Empregou-se máquina de varredura e microscópio estereoscópico para as avaliações da população acarina. A adição de Natur'l Óleo pode afetar negativamente a eficiência do pyridaben 200 CE e 750 PM e cyhexatin 500 PM, no controle do ácaro-daleprose. Triona e Assist não afetaram as eficiências dos acaricidas testados. Pelo índice de iodo, mediu-se o grau de insaturação das misturas dos acaricidas com Natur'l Óleo, concluindo-se que houve incorporação das moléculas dos acaricidas pelas ligações insaturadas do óleo; porém, isto não explica o diferente comportamento dos produtos no controle do ácaro da leprose dos citros.
\end{abstract}

Termos para indexação: sinergismo, eficiência, antagonismo, adjuvantes.

\section{EFFECT OF MINERAL AND VEGETAL OILS ON THE EFFICACY OF MITICIDES IN CONTROL OF THE CITRUS LEPROSIS MITES Brevipalpus phoenicis (GEIJSKES) (ACARI: TENUIPALPIDAE)}

\begin{abstract}
Aiming to study the influence of adition of oil to acaricides, a field experiment was conducted in 1994, at Viradouro, SP, using Assist, Triona and Natur'l Óleo, in dosages of $500 \mathrm{~mL}$ per 100 liters of water, added to the acaricides: pyridaben (formulations $200 \mathrm{EC}$ and $750 \mathrm{WP}$ ) at $75 \mathrm{~mL}$ and $20 \mathrm{~g}$; propargite $720 \mathrm{EC}$ at $100 \mathrm{~mL}$; fenbutatine oxide $500 \mathrm{SC}$ at $80 \mathrm{~mL}$; and cyhexatin $500 \mathrm{WP}$ at $50 \mathrm{~g}$. The experimental design used was randomized blocks. The applications were carried out by a gun sprayer. After the preparation of the solution, the $\mathrm{pH}$ was determined. The brushing machine and the steroscopic microscope were used to estimate the mite populations. The addition of Natur'l Óleo can affect negatively the efficiency of acaricides in the control of the citrus leprosis mite, as occured with pyridaben $200 \mathrm{EC}$ and $750 \mathrm{WP}$ and cyhexatin $500 \mathrm{WP}$. Triona and Assist did not affect the efficiency of the acaricides tested. The insaturation level of the acaricide mistures with Natur'l Óleo was measured using the iodine index method indicating that there was incorporation of the acaricide molecules by the insaturated links of the oil; however, this doesn't explain the different behavior of the products in the control of the citrus leprosis mite.
\end{abstract}

Index terms: synergism, efficiency, antagonism, adjuvant.

\section{INTRODUÇÃO}

O Brasil é o maior produtor de citros do mundo seguido dos Estados Unidos e da China.

A cultura citrícola é, entre as frutíferas, a que demanda maior quantidade de defensivos agrícolas, constituindo-se um dos principais componentes do custo de produção da cultura, segundo a AGRIANUAL, 2000, que visam a controlar acarinos, principalmente o ácaro-da-leprose dos citros, Brevipalpus phoenicis (Geijskes 1939), considerado seu transmissor. Trata-se de um ácaro polífago, podendo ser também encontrado em outras culturas e em plantas ornamentais (Oliveira, 1986; Trindade, 1990).

A leprose dos citros constitui-se em uma das principais doenças, devido à grande perda que pode acarretar. É uma doença cujas evidências levam a crer ser a mesma causada por uma entidade viral, dada a possibilidade de sua transmissão por enxertia e por meios mecânicos, e a consistente presença de bastonetes similares a outros vírus descritos (Kitajima et al., 1972; Chagas e Rossetti, 1980; Colariccio et al., 1995; Kitajima et al., 1995; Rosetti, 1995).

Os sintomas da leprose podem manifestar-se em folhas, ramos e frutos. Nas folhas, surgem manchas, inicialmente amareladas com pontuações escuras e, posteriormente, necrosadas. Nos ramos afetados, há presença de manchas marrons que, depois secam e destacam-se, provocando sua morte. Em frutos, o sintoma se manifesta através de manchas marrons deprimidas (Bitancourt, 1940).

As plantas doentes têm capacidade fotossintética baixa, os ramos secam e há queda prematura das folhas. Quando há incidência severa da doença, o pomar pode tornar-se economicamente inviável (Oliveira et al., 1991). Para que isso não aconteça, o produtor deve manejar o seu pomar adequadamente, usando todas as estratégias para ga- rantir a produtividade.

Entre as várias medidas de controle do transmissor, destaca-se o tratamento químico mediante o emprego de acaricidas.

A mistura de defensivos não tem sido uma recomendação generalizada, porém, muitos agricultores a utilizam, objetivando melhorar a eficiência no controle. A adição de óleo tem sido relativamente frequiente, todavia, pouco se conhece sobre seus efeitos na eficácia de acaricidas.

Nesse sentido, foi desenvolvido o presente estudo que teve por objetivo avaliar os efeitos da adição de óleos mineral e vegetal aos acaricidas, visando o controle do ácaro da leprose dos citros.

\section{MATERIALEMÉTODOS}

O ensaio foi conduzido em pomar da Fazenda Novo Mundo, de propriedade do Sr. Antônio Luppi, no município de Viradouro, SP, em um talhão de laranjeiras da variedade Natal, com 6 anos de idade, plantadas no espaçamento $6 \times 7$ metros. As plantas encontravam-se medianamente enfolhadas, em razão da prolongada estiagem. Durante a condução do experimento ficaram suspensos quaisquer outros tratamentos fitossanitários com a finalidade de não prejudicar o programa experimental. Adotou-se o delineamento experimental de blocos casualizados onde 21 tratamentos foram repetidos 4 vezes. Os blocos foram constituídos de plantas que possuíam aproximadamente o mesmo número de ácaros, não se levando em consideração a localização das plantas no pomar. Cada unidade experimental constou de 3 plantas, sendo considerada como planta útil a central, e as demais, como bordadura.

Para cada $100 \mathrm{~L}$ de água foram estabelecidos os seguintes tratamentos: $500 \mathrm{~mL}$ de óleo mineral (Assist ou Triona) ou vegetal (Natur'1 Óleo) adicionados às caldas dos acaricidas pyridaben nas formulações CE e PM (Sanmite), respectivamente $75 \mathrm{~mL}$ e $20 \mathrm{~g} ; 100 \mathrm{~mL}$ de propargite

${ }^{1}$ (Trabalho 149/2002). Recebido: 6/11/2002. Aceito para publicação: 30/04/2003.

${ }^{2}$ Departamento de Fitossanidade da FCAV/UNESP, Via de Acesso Prof. Paulo Donato Castellane, s/n, 14884-900 - Jaboticabal, SP. E-mail: amadeu@ @cav.unesp.br. ${ }^{3}$ Departamento de Tecnologia da FCAV/UNESP, Via de Acesso Prof. Paulo Donato Castellane, s/n, 14884-900 - Jaboticabal, SP. E-mail: wjmelo@ fcav.unesp.br.

Rev. Bras. Frutic., Jaboticabal - SP, v. 25, n. 2, p. 224-226, Agosto 2003 
(Omite 720 CE BR); $80 \mathrm{~mL}$ de óxido de fenbutatina (Torque $500 \mathrm{SC}$ ), $50 \mathrm{~g}$ de cyhexatin (Hokko Cyhexatin 500 PM).

A aplicação dos produtos foi efetuada em 19/10/94, com auxílio de um pulverizador tipo pistola, dotado de bico D6, tracionado por trator regulado a uma pressão aproximada de $300 \mathrm{lbf} / \mathrm{pol}^{2}$ e gastando-se 15 litros por planta, até o ponto de escorrimento da calda. Após a preparação da calda e agitação para homogeneização, ou seja, momentos antes da aplicação, foi determinado o $\mathrm{pH}$, através de um $\mathrm{pH}$-metro portátil.

Foram realizados vários levantamentos populacionais do ácaro da leprose no decorrer da condução do ensaio, tendo sido efetuado um antes, em 18/10/94 e os demais a 9, 23 e 37 dias após a aplicação. Coletaram-se, ao acaso, 10 frutos com sintomas de verrugose, colhidos ao redor da copa das árvores (Martinelli et al., 1976). As amostras de frutos foram acondicionadas em sacos de papel identificados e transportados para o laboratório de Acarologia da FCAV-UNESP, Câmpus de Jaboticabal. A retirada dos ácaros dos frutos foi feita com o auxílio de uma máquina de varredura. Os acarinos coletados na placa de vidro do equipamento foram contados com o auxílio de um microscópio estereoscópico (Oliveira, 1983).

Os dados meteorológicos registrados (precipitação e temperatura) 2 meses antes e durante a condução do experimento, foram fornecidos pela Estação Meteorológica da Estação Experimental de Citricultura de Bebedouro, por encontrar-se próxima ao local do experimento.

Os dados observados nos levantamentos foram transformados em $\log (x+1,50)$ e analisados pelo teste $F$ e Tukey no esquema fatorial de 2 fatores com testemunha (sem óleo) ( $5 \times 4$ ), sendo 5 produtos e 4 óleos. Determinou-se o grau de insaturação das misturas aparentes (acaricidas + óleos) através do teste de índice de iodo pelo método de Hübl (Instituto Adolfo Lutz, 1985).

\section{RESULTADOSE DISCUSSÃO}

Os valores de $\mathrm{pH}$ das caldas de pulverização, determinados momentos antes da aplicação, indicam que os acaricidas adicionados à água causaram uma diminuição do $\mathrm{pH}$ da ordem de 0,46 , em média, em relação ao da água, o mesmo acontecendo com os acaricidas mais o Assist $(0,57)$ e Natur'l Óleo $(0,47)$. Todavia, as misturas de acaricidas com Triona acarretam, em média, um acréscimo no pH da ordem de 0,51 .
A adição de óleos Assist e Natur'l Óleo pouco influiu no pH, uma vez que as reduções registradas foram muito próximas às reduções causadas pelos acaricidas; em contrapartida, o Triona causou um aumento em relação ao pH das caldas (água + acaricidas) de aproximadamente 1. A despeito desse acréscimo, a eficiência biológica dos acaricidas no controle do ácaro da leprose parece não ter sido afetada devido a essas alterações (Tabela 1).

Pela análise dos dados relativos ao levantamento prévio, constata-se que a área experimental encontrava-se uniformemente infestada, com nível populacional considerado elevado, ideal para estudos dessa natureza.

Verificou-se que, após 9 dias (Tabela 2), os acaricidas aplicados isoladamente apresentaram alta eficiência no controle do ácaro da leprose, não diferindo estatisticamente entre si; todavia, o mesmo não se observou com relação às misturas de acaricidas com óleos, onde o Natur'lóleo teve uma influência negativa, o que não ocorreu em relação ao Triona.

Decorridos 23 e 37 dias da aplicação (Tabelas 2 e 3), os produtos pyridaben $750 \mathrm{PM}$, propargite $720 \mathrm{CE}$, óxido de fenbutatina $500 \mathrm{SC}$ e cyhexatin 500 PM mostraram-se ligeiramente superiores ao pyridaben 200 CE. A alta eficiência desses produtos, exceto o pyridaben $200 \mathrm{CE}$, foi comprovada por Oliveira et al., 1991. Quanto à adição de óleos, verificouse que o Natur'l Óleo prejudicou a eficiência do pyridaben 750 PM e cyhexatin, não se registrando nenhum efeito negativo sobre propargite $\mathrm{e}$ óxido de fenbutatina.

Para pyridaben 200 CE não houve diferença significativa ao tratamento sem óleo; já os óleos Assist e Triona (minerais) diferem do tratamento sem óleo e portanto podem ter seu efeito positivo considerado.

Cottas (1991) constatou que o óxido de fenbutatina 500 SC em mistura com óleo mineral Triona e óleo vegetal Natur'l Óleo, não teve sua eficiência melhorada em função da adição dos óleos.

Com relação ao Assist e Triona (Tabela 3), observou-se que esses óleos minerais não afetaram a eficácia de quaisquer dos produtos testados. Ressalta-se que o experimento foi conduzido após um período de prolongada estiagem com plantas apresentando um acentuado estresse hídrico, voltando a chover dias após a aplicação, o que provavelmente tenha causado direta ou indiretamente a diminuição da população na testemunha.

TABELA 1 - Totais de ácaros-da-leprose, Brevipalpus phoenicis, observados nos levantamentos prévio e após a aplicação dos produtos. Viradouro, SP, de 18/10/94 a 25/11/94.

\begin{tabular}{|c|c|c|c|c|c|c|}
\hline \multirow[t]{2}{*}{ Tratamentos } & \multirow{2}{*}{$\begin{array}{l}\text { Dosagem g ou ml } \\
\text { pc/100L água }\end{array}$} & \multirow{2}{*}{$\begin{array}{l}\text { Prévia } \\
(18 / 10)\end{array}$} & \multicolumn{3}{|c|}{ Dias após a aplicação } & \multirow{2}{*}{$\sum_{\text {Totais }}^{\sum}$} \\
\hline & & & 9 & 23 & 37 & \\
\hline 1. Pyridaben $200 \mathrm{CE}+$ Asssit & $75+500$ & 1241 & 0 & 2 & 0 & 2 \\
\hline 2. Pyridaben $200 \mathrm{CE}+$ Triona & $75+500$ & 1140 & 0 & 4 & 10 & 14 \\
\hline 3. Pyridaben $200 \mathrm{CE}+$ Natur'l Óleo & $75+500$ & 1032 & 18 & 63 & 94 & 175 \\
\hline 4. Pyridaben $200 \mathrm{CE}$ & 75 & 1026 & 13 & 48 & 35 & 96 \\
\hline 5. Pyridaben $750 \mathrm{PM}+$ Assist & $20+500$ & 1043 & 2 & 2 & 2 & 6 \\
\hline 6. Pyridaben $750 \mathrm{PM}+$ Triona & $20+500$ & 1048 & 0 & 14 & 15 & 29 \\
\hline 7. Pyridaben 750 PM + Natur'1 Óleo & $20+500$ & 1077 & 139 & 46 & 46 & 231 \\
\hline 8. Pyridaben $750 \mathrm{PM}$ & 20 & 1080 & 0 & 0 & 2 & 2 \\
\hline 9. Propargite $720 \mathrm{CE}+$ Assist & $100+500$ & 1051 & 0 & 0 & 0 & 0 \\
\hline 10. Propargite $720 \mathrm{CE}+$ Triona & $100+500$ & 1024 & 0 & 0 & 0 & 0 \\
\hline 11. Propargite $720 \mathrm{CE}+$ Natur'l Óleo & $100+500$ & 1031 & 0 & 0 & 0 & 0 \\
\hline 12. Propargite $720 \mathrm{CE}$ & 100 & 1018 & 0 & 0 & 0 & 0 \\
\hline 13. Óxido de fenbutatina $500 \mathrm{SC}+$ Assist & $80+500$ & 1005 & 0 & 1 & 0 & 1 \\
\hline 14. Óxido de fenbutatina $500 \mathrm{SC}+$ Triona & $80+500$ & 1000 & 0 & 4 & 0 & 4 \\
\hline 15. Óxido de fenbutatina $500 \mathrm{SC}+$ Natur'1 Óleo & $80+500$ & 1007 & 1 & 0 & 0 & 1 \\
\hline 16. Óxido de fenbutatina $500 \mathrm{SC}$ & 80 & 1090 & 8 & 0 & 0 & 8 \\
\hline 17. Cyhexatin $500 \mathrm{PM}+$ Assist & $50+500$ & 1003 & 6 & 4 & 3 & 13 \\
\hline 18. Cyhexatin $500 \mathrm{PM}+$ Triona & $50+500$ & 1010 & 0 & 1 & 4 & 5 \\
\hline 19. Cyhexatin 500 PM + Natur'l Óleo & $50+500$ & 1004 & 1 & 37 & 29 & 67 \\
\hline 20. Cyhexatin 500 PM & 50 & 1034 & 0 & 0 & 1 & 1 \\
\hline 21. Testemunha & - & 1097 & 1348 & 460 & 75 & 1883 \\
\hline
\end{tabular}


TABELA 2 -Números médios de Brevipalpus phoenicis transformados em log (x + 1,5), observados nos levantamentos populacionais efetuados 9,23 e 37 dias da aplicação.

\begin{tabular}{|c|c|c|c|c|}
\hline & & & Levantamentos (dias) & \\
\hline & & 9 & 23 & 37 \\
\hline & Pyridaben $200 \mathrm{CE}$ & 0,75 a $[ \pm 0,16](16)^{2}$ & 1,59 a $[ \pm 0,14](16)$ & 1,70 a $[ \pm 0,11](16)$ \\
\hline & Pyridaben 750 PM & 0,91 a $[ \pm 0,16](16)$ & $1,13 \mathrm{ab}[ \pm 0,14](16)$ & $1,20 \mathrm{~b}[ \pm 0,14](16)$ \\
\hline Acaricidas & Propargite $720 \mathrm{CE}$ & 0,41 a $[ \pm 0,16](16)$ & $0,41 \mathrm{c}[ \pm 0,14](16)$ & 0,41 c $[ \pm 0,11](16)$ \\
\hline & Óxido de fenbutatina $500 \mathrm{SC}$ & 0,59 a $[ \pm 0,16](16)$ & $0,52 \mathrm{c}[ \pm 0,14](16)$ & $0,41 \mathrm{c}[ \pm 0,11](16)$ \\
\hline & Cyhexatin 500 PM & $0,54 \mathrm{a}[ \pm 0,16](16)$ & $0,87 \mathrm{bc}[ \pm 0,14](16)$ & $1,04 \mathrm{~b}[ \pm 0,11](16)$ \\
\hline & Assist & $0,53 \mathrm{ab}[ \pm 0,14](20)$ & $0,59 \mathrm{~b}[ \pm 0,13](20)$ & $0,52 \mathrm{~b}[ \pm 0,10](20)$ \\
\hline & Triona & $0,41 \mathrm{~b}[ \pm 0,14](20)$ & $0,73 \mathrm{~b}[ \pm 0,13](20)$ & $0,78 \mathrm{~b}[ \pm 0,10](20)$ \\
\hline Óleos & Natur'l Óleo & 0,94 a $[ \pm 0,14](20)$ & $1,50 \mathrm{a}[ \pm 0,13](20)$ & 1,67 a $[ \pm 0,10](20)$ \\
\hline & Sem Óleo & $0,68 \mathrm{ab}[ \pm 0,14](20)$ & $0,79 \mathrm{~b}[ \pm 0,13](20)$ & $0,84 \mathrm{~b}[ \pm 0,10](20)$ \\
\hline Teste F (Acaricidas x Óleos) & & $1,90 \mathrm{~ns}$ & $4,21 * *$ & $6,18 * *$ \\
\hline Teste $\mathrm{F}$ (Testemunha $\mathrm{x}$ Fatores) & & $241,01 * *$ & $170,10 * *$ & $6,28 * *$ \\
\hline
\end{tabular}

$241,01 * *$

$6,28 * *$

Médias seguidas de mesma letra na coluna não diferem estatisticamente entre si pelo teste Tukey $(\mathrm{P} \leq 0,05)$

2 [EP] - erro padrão da média; (n) - número de repetições

TABELA 3 - Comparação de médias do número de Brevipalpus phoenicis, transformados em log (x + 1,5), observado em frutos, nos levantamentos realizados 23 a 37 dias da aplicação.

\begin{tabular}{|c|c|c|c|c|c|c|c|}
\hline \multirow[b]{2}{*}{$\begin{array}{l}\text { Dias após } \\
\text { a aplicação }\end{array}$} & \multirow[b]{2}{*}{ Óleos } & \multicolumn{6}{|c|}{ Acaricidas } \\
\hline & & $\begin{array}{c}\text { Pyridaben } \\
220 \mathrm{CE}\end{array}$ & $\begin{array}{c}\text { Pyridaben } \\
750 \text { PM }\end{array}$ & $\begin{array}{c}\text { Propargite } \\
720 \mathrm{CE}\end{array}$ & $\begin{array}{l}\text { Óxido de } \\
\text { fenbutatina } \\
500 \mathrm{SC}\end{array}$ & $\begin{array}{c}\text { Cyhexatin } \\
500 \text { PM }\end{array}$ & $\begin{array}{c}\text { Teste } \\
\text { F }\end{array}$ \\
\hline & Assist & $0,62 \mathrm{bA}^{(1)}$ & $0,66 \mathrm{bA}$ & $0,41 \mathrm{aA}$ & $0,53 \mathrm{aA}$ & $0,73 \mathrm{abA}$ & $0,19 \mathrm{~ns}$ \\
\hline & Triona & $0,73 \mathrm{bA}$ & $1,24 \mathrm{abA}$ & $0,41 \mathrm{aA}$ & $0,73 \mathrm{aA}$ & $0,53 \mathrm{bA}$ & $1,23 \mathrm{~ns}$ \\
\hline & Natur'1 Óleo & $2,69 \mathrm{aA}$ & $2,22 \mathrm{aA}$ & $0,41 \mathrm{aB}$ & $0,41 \mathrm{aB}$ & $1,80 \mathrm{aA}$ & $13,45 * *$ \\
\hline & Sem Óleo & $2,33 \mathrm{aA}$ & $0,41 \mathrm{bB}$ & $0,41 \mathrm{aB}$ & $0,41 \mathrm{aB}$ & $0,41 \mathrm{bB}$ & $9,01 * *$ \\
\hline & Assist & $0,41 \mathrm{bA}$ & $0,62 \mathrm{bA}$ & $0,41 \mathrm{aA}$ & $0,41 \mathrm{aA}$ & $0,75 \mathrm{bA}$ & $0,49 \mathrm{~ns}$ \\
\hline & Triona & $1,22 \mathrm{bA}$ & $1,12 \mathrm{bA}$ & $0,41 \mathrm{aA}$ & $0,41 \mathrm{aA}$ & $0,73 \mathrm{bA}$ & $2,91 *$ \\
\hline & Natur'1 Óleo & $2,99 \mathrm{aA}$ & $2,40 \mathrm{aA}$ & $0,41 \mathrm{aB}$ & $0,41 \mathrm{aB}$ & $2,15 \mathrm{aA}$ & $27,94 * *$ \\
\hline & Sem Óleo & $2,17 \mathrm{aA}$ & $0,66 \mathrm{bB}$ & $0,41 \mathrm{aB}$ & $0,41 \mathrm{aB}$ & $0,53 \mathrm{bB}$ & $11,17 * *$ \\
\hline
\end{tabular}

${ }^{(1)}$ Médias seguidas de mesma letra minúscula na coluna e maiúscula na linha não diferem estatisticamente entre si pelo teste Tukey $(\mathrm{P} \leq 0,05)$

Pelos índices de iodo calculados (Tabela 4), pode-se constatar que as ligações insaturadas do óleo incorporam as moléculas de todos os acaricidas e não apenas daquelas que, no campo, foram menos eficientes em misturas com óleo; portanto, pelo teste efetuado não se pode inferir que o grau de insaturação tenha sido o responsável pela diminuição da eficiência dos acaricidas em misturas com óleos.

TABELA 4 -Valores do índice do Hübl.

\begin{tabular}{lc}
\hline Tratamentos & Índice de Hübl \\
\hline Propargite 720 CE + Natur'l Óleo + água & $0,2626 \mathrm{a}^{(1)}$ \\
Cyhexatin 500 PM + Natur'1 Óleo + água & $0,2854 \mathrm{a}$ \\
Óxido de fenbutatina 500 SC + Natur'l Óleo + água & $0,2865 \mathrm{a}$ \\
Pyridaben 750 PM + Natur'l Óleo + água & $0,2601 \mathrm{a}$ \\
Natur'l Óleo & $0,3479 \mathrm{~b}$ \\
\hline
\end{tabular}

${ }^{(1)}$ Médias seguidas de mesma letra na coluna não diferem estatisticamente entre si pelo teste Tukey $(\mathrm{P} \leq 0,05)$.

A diferença de comportamento entre o óleo vegetal e o mineral, provavelmente, seja em decorrência de suas composições, uma vez que o mineral é proveniente da destilação do petróleo, fração mais homogênea, e o vegetal é composto por um conjunto de diferentes gorduras, quimicamente distintas, normalmente insaturadas, heterogêneo e mais facilmente oxidável, o que pode afetar a eficácia do acaricida.

Outro aspecto que necessita ser melhor pesquisado é quanto ao efeito das chuvas sobre as misturas dos acaricidas pyridaben e cyhexatin com Natur'lóleo.

\section{REFERÊNCIASBIBLIOGRÁFICAS}

AGRIANUAL, 2000: anuário da agricultura brasileira. São Paulo: FNP Consultoria e Comércio, 1999. 546p.

BITANCOURT, A.A. A leprose dos citrus. Biológico, São Paulo, 6:39-45, 1940.

CHAGAS, C.M.; ROSSETTI, V. Transmissão experimental da leprose dos citros por meio de implantação de tecido foliar no caule. Fitopatologia Brasileira, Brasília, v. 6, p. 211-214, 1980.
COLARICCIO, A.; LOVISOLO, O.; CHAGAS, C.M.; GALLETTI, S.R.; ROSSETTI, V.; KITAJIMA, E.W. Mechanical transmission and ultrastructural aspects of citrus leprosis desease. Fitopatologia Brasileira, Brasília, v. 20, p. 208-13, 1995.

COTTAS, M.P. Óxido de fenbutatina em mistura com óleos. Informe Coopercitrus, Bebedouro, 54:26-27, 1991.

KITAJIMA, E.W.; MÜLLER, G.W.; COSTA, A.S.; YUKI, V.A. Short rodlike particles associated with citrus leprosis. Virology, Orlando, v. 50, p. 254-258, 1972

KITAJIMA, E.W.; LOVISOLO, O.; COLARICCIO, A.; CHAGAS, C.M.; ROSSETTI, V. Vírus causador da leprose dos citros. p.19-23. In: OLIVEIRA, C.A.L. de; DONADIO, L.C. (Ed) Leprose dos Citros. Jaboticabal: FUNEP, 1995.219p.

INSTITUTO ADOLFO LUTZ. Normas analíticas: métodos químicos e físicos para análise de alimentos. 4. ed. São Paulo, 1985. p. 193-194.

MARTINELLI, N.M.; OLIVEIRA, C.A.L. de; PERECIN, D. Conhecimentos básicos para estudos que envolvam levantamentos da população do Brevipalpus phoenicis (Geijskes, 1939) na cultura de citros. Científica, Jaboticabal, v. 4, n. 3, p. 242-253, 1976.

OLIVEIRA, C.A.L. de. Flutuação populacional e medidas de controle do ácaro da leprose Brevipalpus phoencis (Geijskes, 1939) em citros. Laranja, Cordeirópolis, 1-31, 1986.

OLIVEIRA, C.A.L. de. Máquinas de varredura de ácaro "modelo Jaboticabal". Anais da Sociedade Entomológica do Brasil, Piracicaba, v. 2, p. 299-303, 1983.

OLIVEIRA, C.A.L. de, SANTOS, J.R. dos; SALA, I. Ácaro da leprose dos citros: resultados de 104 ensaios de campo visando seu controle, 19851990. Jaboticabal: FUNEP, 1991.56p (Boletim Técnico).

ROSSETTI, V. A leprose dos citros no Brasil. P.1-12. In: OLIVEIRA, C.A.L. de; DONADIO, L.C. (Ed) Leprose dos Citros. Jaboticabal: FUNEP, 1995. 219p.

TRINDADE, M.L.B. Caracterização biológica dos ácaros Brevipalpus obovatus (Donnadieu, 1875), Brevipalpus californicus (Banks, 1904) e Brevipalpus phoenicis (Geijskes, 1939) (Acari: Tenuipalpidae) no Estado de São Paulo. 1990. 108f. Dissertação (Mestrado) - Faculdade de Ciências Agronômicas, Universidade Estadual Paulista, Botucatu, 1990. 